Agrotrópica 33(3): 159 - 172. 2021.

Centro de Pesquisas do Cacau, Ilhéus, Bahia, Brasil

\title{
EFEITOS DOS PREÇOS INTERNACIONAIS E DA TAXA DE CÂMBIO SOBRE OS PREÇOS DOMÉSTICOS DE CACAU EM AMÊNDOAS
}

\author{
Antonio Cesar Costa Zugaib ${ }^{1,2}$, Lindolfo Pereira dos Santos Filho ${ }^{1}$
}

${ }^{1}$ CEPLAC - km 22, Rod. Ilhéus-Itabuna. 45600-970, Itabuna-Bahia. ${ }^{2}$ UESC - Rod. Ilhéus-Itabuna, km 16 - Salobrinho. Ilhéus- Bahia. antonio.zugaib@agro.gov.br

\begin{abstract}
A determinação do preço de cacau e suas consequentes oscilações é um problema enfrentado pelos países produtores de cacau. Como os preços do cacau praticados nesses países tem origem nas Bolsas de Londres e de Nova York, os quais são determinados pelas forças que influenciam o mercado internacional de produtos agrícolas, pouco resta aos países produtores para administrar esses preços. O objetivo deste trabalho é avaliar as influências das políticas cambiais e dos preços internacionais, no preço doméstico do cacau em amêndoas, no período de 1994 a 2020 , período este correspondente ao plano real. Utilizou-se como metodologia o modelo shift-share, também chamado "diferencial-estrutural". Analisaram os efeitos da taxa de câmbio real e do preço nominal internacional do cacau em amêndoas sobre o preço real em reais da commoditie agrícola no mercado doméstico. Conclui-se que no período estudado de 1994 a 2020, referente ao plano real, verifica-se que a participação do efeito preço na formação do preço interno real foi mais contundente do que o efeito câmbio, confirmando os resultados obtidos por Reis e Campos (1998), no período entre 1975 a 1995 e também por Soares, Costa e Lemos (2016) no período entre 1990 a 2010. O ano de 2002 teve a maior taxa de crescimento (efeito total) de $71 \%$ a.a. proporcionando participação positiva nos preços (efeito preços) de 64\% a.a. Assim como, o ano de 2017 teve a menor taxa de crescimento (efeito total) de - 32,6\% a.a. proporcionado participação negativa no preço (efeito preço) com queda de -29\% a.a., como também, uma participação negativa no câmbio de $-3,5 \%$ a.a., ambos contribuindo para termos uma taxa de crescimento negativa. Entre 2003 e 2011 o fator câmbio teve uma influência negativa muito grande nas taxas de crescimento negativa, mesmo quando se obteve efeitos totais positivos neste período, o efeito câmbio sempre se comportou com variações negativas, tendo menores participações na formação dos preços reais domésticos, destacando-se uma participação positiva somente nos anos 2015, 2016 e 2020. As diferenças de inflação entre Brasil e Estados Unidos contribuíram para reduzir o efeito da taxa de câmbio real no ano de 2020, praticamente anulando a desvalorização cambial. Porém, se não houvesse a desvalorização cambial adotada, a perda de competitividade do cacau em amêndoas seria bem maior.
\end{abstract}

Palavras-chave: Desvalorização cambial, preço real, inflação, shift-share.

\section{Effects of international prices and exchange rate on domestic prices cocoa in}

beans. The determination of cocoa prices and their consequent fluctuations is a problem faced by cocoa producing countries. As cocoa prices practiced in these countries and originate in the London and New York Stock Exchanges, which are determined by the forces that influence the international market for agricultural products, there is little left for producing countries to manage these prices. The objective of this work is to evaluate the influence of exchange rate policies and international prices on the domestic price of cocoa beans, from 1994 to 2020, a period corresponding to the real plan. The shift-share model, also called "structural-differential" was used as a methodology. They analyzed the effects of the real exchange rate and the nominal international price of cocoa beans on the real price in reais of the agricultural commodity in the domestic market. It is concluded that in the period studied from 1994 to 2020, referring to the real plan, it is verified that the participation of the price effect in the formation of the real domestic price was stronger than the exchange effect, confirming the results obtained by Reis and Campos (1998), in the period between 1975 and 1995 and also by Soares, Costa and Lemos (2016) in the period between 1990 and 2010. The year 2002 had the highest growth rate (total effect) of $71 \%$ pa providing a positive share in prices (price effect) of 64\% p.a. Likewise, the year 2017 had the lowest growth rate (total effect) of $-32.6 \%$ p.a. providing a negative participation in the price (price effect) with a drop of $-29 \%$ p.a., as well as a negative participation in the exchange rate of $-3.5 \%$ p.a., both contributing to our negative growth rate. Between 2003 and 2011 the exchange factor had a very large negative influence on negative growth rates, even when there were positive total effects in this period, the exchange effect always behaved with negative variations, having smaller participation in the formation of real domestic prices, highlighting a positive participation only in the years 2015 , 2016 and 2020. The differences in inflation between Brazil and the United States helped to reduce the effect of the real exchange rate in 2020, practically canceling the exchange devaluation. However, if there were no exchange devaluation adopted, the loss of competitiveness of cocoa in almonds would be much greater.

Key words: Currency devaluation, real price, inflation, Shift-share. 


\section{Introdução}

O mercado internacional de cacau teve seu auge em 1976/77 quando o estoque mundial estava apenas com 274 mil toneladas e os preços atingiram US\$3.632/ t. O Brasil se encontrava na segunda posição na produção de cacau no mercado internacional. A partir daí os países africanos em virtude dos preços altos começaram a se interessar pela cultura do cacau e expandiram suas plantações. A produção mundial de cacau começou a crescer e depois de sete superávits consecutivos entre 1984/85 e 1990/91, os estoques mundiais de cacau em amêndoas cresceram e passaram de 593 mil toneladas para 1.647 milhão de toneladas neste mesmo período. Isto fizeram com que os preços declinassem de US\$ 2.222/t para US\$ 1.193/t.

A partir de 1981/82 foi implementado uma política de buffer-stock pela Organização Internacional do Cacau - ICCO visando aumentar os preços com a retirada anual de 100 mil t do mercado internacional até 1985/86. Essa estratégia fez com que os preços tivessem uma leve reação passando de US\$ 1.868/t em 1981/82 para US \$2.149/t em 1985/86. Então houve uma nova tentativa para elevar os preços, ainda mais, sendo retirado do mercado anualmente uma média de 214 mil t no período entre 1986/87 e 1992/93. Porém, esta redução na oferta não proporcionou uma elevação dos preços do cacau, pelo contrário, os preços caíram de US\$2.023/t para US\$ 1.440/t no mesmo período. Não obtendo êxito com a política do buffer-stock, os países signatários resolveram terminar com essa estratégia mal sucedida, e liquidar todo o estoque regulador em 1996/97.

A produção mundial, assim como, as moagens de cacau em amêndoas têm crescido durante todo o período entre 1960/61 a 2020/21. Por diversas vezes neste período a produção mundial de cacau em amêndoas passaram as moagens (medida de consumo no mercado de cacau em amêndoas) e as moagens passaram a produção. A taxa geométrica de crescimento - TGC média da produção neste período é de $2,5 \%$ a.a. e das moagens de $2,7 \%$ a.a. Após a alta dos preços de 1976/77 uma boa reação nos preços do cacau ocorreu apenas na safra 2009/2010 quando os preços alcançaram US\$3.246/t provocada por uma redução nos estoques para 1.418 milhão t. Com o aumento dos estoques em 2011/2012 para 1.893 milhão $t$. os preços voltaram a cair para US\$2.396/t demonstrando grande instabilidade. Atualmente (2020/ 21) os estoques estão previstos em 1.878 milhão t e os preços em US\$2.386/t. Pela primeira vez no mercado internacional a produção rompe a casa de 5 milhões de toneladas. A previsão é que a produção mundial alcance 5.024 milhões t, enquanto as moagens 4.809 milhões t, proporcionando um superávit em torno de 165 mil t. Gráfico 1.

De acordo com Reis e Campos (1998) um grande problema enfrentado pelos países produtores, principalmente os produtores de cacau é a variação dos preços desse produto. Como os preços do cacau praticados nesses países tem origem nas Bolsas de Londres e de Nova York, os quais são determinados pelas forças que influenciam o mercado internacional de produtos agrícolas, pouco resta aos países produtores para reduzir a volatilidade desses preços.

O cacau, por ser uma commodity agrícola com cotação internacional, nas bolsas de Nova Iorque e Londres, é suscetível às oscilações de preço em decorrência de oferta e demanda mundial. Para o mercado brasileiro utiliza-se como referência a bolsa de Nova Iorque.

Para Amim (1988), citado por Reis e Campos (1998), a variação de preços deve-se, basicamente, a dois importantes fatores: do lado da oferta, a produção de cacau é totalmente dependente das condições climáticas nas regiões produtoras e, do lado da procura, o cacau confronta-se, na maioria dos países importadores, com uma procura preço-inelástica. A ação combinada desses dois fatores faz com que o cacau tenha um dos mais altos níveis de variação nos preços.

De acordo com as cotações na bolsa de mercadorias de Nova York, os preços entre 1960 e 2020 apresentaram grandes variações, atingindo seus valores mais altos em 1977/78 e 2009/2010, com US\$ 3.632 e US\$ 3.246/t, respectivamente. Durante esse mesmo período verificou-se uma queda acentuada dos preços verificados nos anos de 1992/93 e 1999/2000, com US\$1.051 e US\$ 919/t, respectivamente, com consequentes efeitos negativos para a economia cacaueira mundial, especificamente para o Brasil, que aliado ao aparecimento da vassoura-de-bruxa, contribuíram para que o país saísse de segundo maior produtor de cacau em amêndoas para o sétimo lugar. 
TGC Produção = 2,5 \% a.a.

TGC Moagens = 2,7 \% a.a.

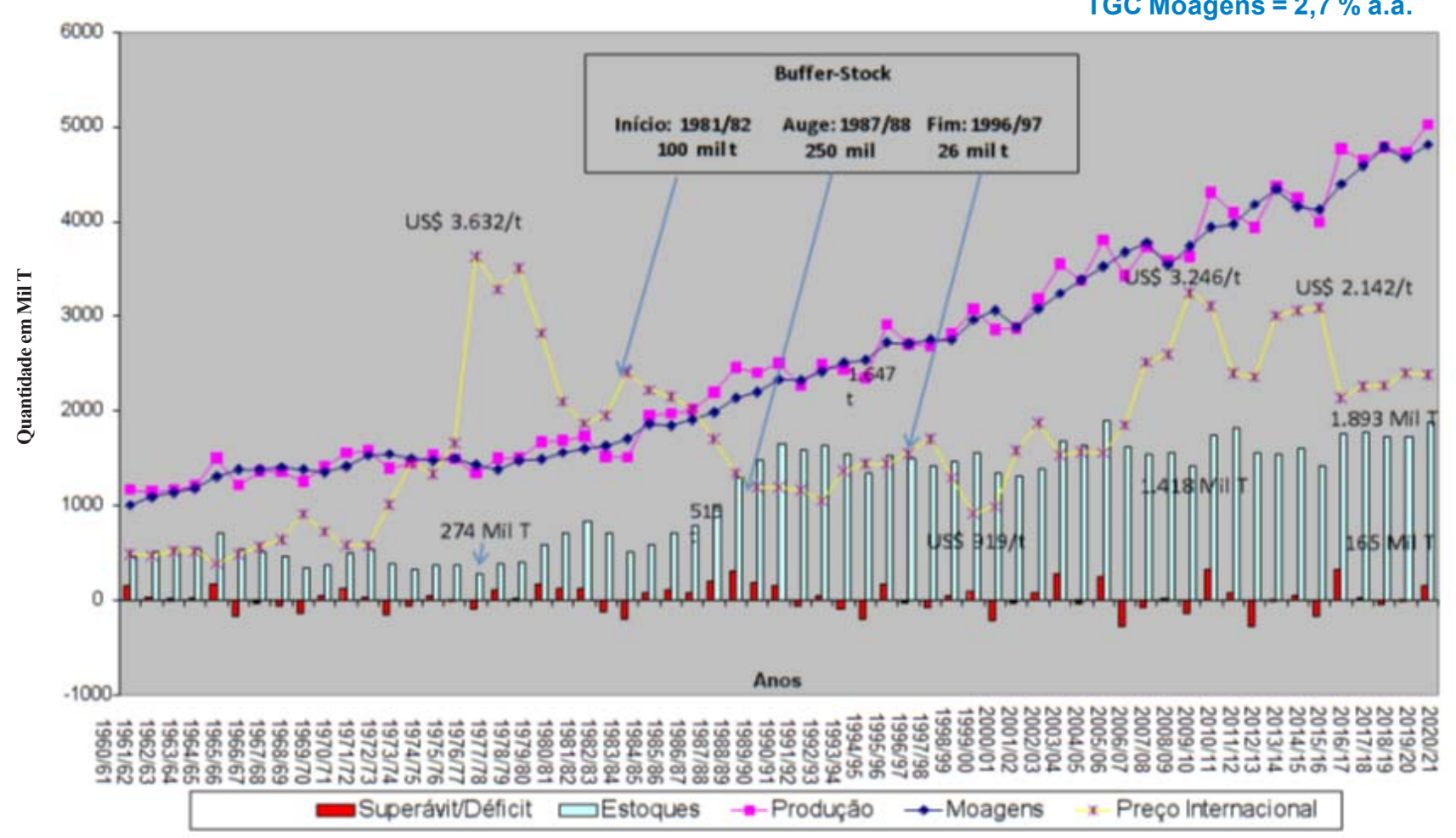

Fonte: ICCO, 2021.

Gráfico 1 - Comportamento da produção, moagens, estoque, superávit/déficit, preços do cacau em amêndoas no mercado internacional.

Um outro fator determinante na formação dos preços no mercado interno é a taxa de câmbio. Uma valorização ou apreciação da taxa de câmbio, corresponde como o aumento do poder de compra da moeda nacional, perante outras moedas (um real compra mais dólares). Uma valorização cambial corresponde a uma queda na taxa de câmbio. Já uma desvalorização cambial ou depreciação cambial representa uma perda no poder de compra da moeda nacional, o que corresponde a um aumento da taxa de câmbio. Vasconcelos (2015).

Segundo Freitas Filho et al. (1993), citado por Reis e Campos (1998), no período compreendido entre 1946 e 1968, houve modificações profundas na estrutura do sistema cambial brasileiro. De 1968 a 1982, ocorreram poucas transformações significantes, exceto a implementação do sistema de minidesvalorizações (implantado em agosto de 1968). A partir de 1982, emergiram paulatinamente, de uma legislação arcaica e emperrada, dois segmentos de mercado de câmbio no Brasil: o oficial (posteriormente chamado de comercial) e o flutuante - ao lado de um atuante mercado paralelo de dólar e de um mecanismo de arbitragem ouro-dólar, via mercado de ouro, implantado a partir de março de 1990.

A partir de 1990, período de maior abertura na economia brasileira, o governo optou por um sistema de câmbio flutuante com intervenção ocasional do Banco Central (flutuação suja), o que provocou grandes variações no valor real do dólar. Em julho de 1994, no início do Plano Real, a taxa de câmbio foi fixada em $\mathrm{R} \$ 1,0 / \mathrm{US} \$ 1,00$, chegando em novembro de 1994 a $\mathrm{R} \$ 0,84 / \mathrm{US} \$ 1,00$, com o preço do dólar cerca de $27 \%$ abaixo do valor fixado; um dos preços mais baixos do dólar desde a implantação do plano. Reis e Campos (1998).

Segundo Sousa, Ferreira e Teixeira (2007), o período compreendido entre 1994 a 1998, com a estabilidade econômica proporcionada pelo plano real em 1994, o câmbio variou menos. A pressão inflacionária era controlada, entre outras formas, por uma taxa de câmbio valorizada, e nesse período foi 
constatada a menor média da taxa de câmbio: $\mathrm{R} \$ 2,47 /$ US\$. Com a introdução do regime cambial flexível em janeiro de 1999, houve desvalorização imediata da taxa de câmbio. Em decorrência da flexibilização, a média da taxa de câmbio foi a mais alta, no período entre 1990 a 2004. Atualmente a política de câmbio flexível continua em vigor situando na média em R \$ 5,35/US\$ no período entre 01 de janeiro e 31 de julho de 2021.

Reis e Campos (1998), analisaram semelhante relação entre os efeitos da taxa de câmbio adotada pelo Brasil e dos preços do cacau na Bolsa de Nova York, sobre os preços do cacau em moeda brasileira, no período entre 1975 e 1995, usando o método de análise shift-share. Considerando os resultados obtidos, observou-se que as variações ocorridas nos preços em moeda brasileira sofreram maior influência das variações dos preços em dólares que das variações da taxa de câmbio.

Da mesma forma Soares, Costa e Lemos (2016), analisaram os efeitos do preço internacional do cacau em amêndoas sobre o preço da commodity no País, pesquisando o impacto na formação dos preços no mercado interno, no período de 1990 a 2010. Utilizaram também o método de análise shift-share e chegaram a conclusão também que os preços em dólar tiveram maior influência sobre os preços em real do que as taxas de câmbio adotadas no período estudado.

Conforme Silva e Carvalho (1995), o efeito preço isola as variações no preço de um produto agrícola, expresso em real, resultante de variações de seu preço no mercado externo, expresso em dólar, e o efeito câmbio segue o mesmo procedimento com a taxa de câmbio.

Neste contexto, o objetivo deste trabalho foi avaliar as influências das políticas cambiais e dos preços internacionais, no preço doméstico do cacau em amêndoas, no período de 1994 a 2020, período este, correspondente ao plano real. Especificamente, pretende-se separar os efeitos dos preços internacionais e da taxa de câmbio sobre o comportamento dos preços do cacau em amêndoas em moeda brasileira, no período de 1994 a 2020. Utilizase como referencial analítico o modelo shift-share, que possibilita a decomposição de taxas de crescimento em fatores que as compõem.

Este tipo de estudo interessa aos órgãos formuladores de políticas e aos tomadores de decisão relativa a cadeia produtiva do cacau, uma vez que podem contribuir para o planejamento da produção, comercialização, além de determinar e analisar o grau de participação dos fatores considerados relevantes na formação do preço interno do cacau em amêndoas.

\section{Metodologia}

\section{Fonte de dados}

Foram utilizados dados de séries temporais mensais e calculadas as médias anuais, de janeiro de 1994 a dezembro de 2020. Praticamente o período correspondente ao plano real.

Os preços do cacau em amêndoas foram cotados através da Bolsa de Nova York e obtidos na Organização Internacional de Cacau - ICCO (www.icco.org). A taxa de câmbio nominal do Brasil (R\$/US\$) é cotada pelo Banco Central do Brasil e foi obtida no próprio site do Banco Central (www.bcb.gov.br).

Foi utilizada a taxa de câmbio real bilateral - IPADI - Brasil/Estados Unidos - índice (média 2010 = 100) calculado pelo Instituto de Pesquisa Econômica Aplicada - IPEA e publicado no próprio site do IPEA (www.ipea.gov.br).

\section{Método shift-share}

Neste trabalho, utilizou-se o modelo shift-share, também chamado "diferencial-estrutural", empregado por Curtis (1972); Yokoyama et al. (1989); Silva e Carvalho (1995); Reis e Campos (1998); Pires, Gomes e Alves (2004); Sousa, Ferreira e Teixeira (2007); Zugaib (2008); Soares, Silva e Rossmann (2013); Soares, Costa e Lemos, 2016; Araújo et al. (2004) entre outros.

Foram utilizadas as abordagens propostas por Silva e Carvalho (1995) e Reis e Campos (1998), que analisaram os efeitos da taxa de câmbio e do preço internacional sobre o preço em reais de commodities agrícolas. Neste trabalho considera-se um horizonte temporal. A análise ano a ano resulta em efeitos correspondentes à variação referente ao ano anterior.

Neste estudo, utilizou-se a taxa de câmbio real obtida das taxas médias anuais do período analisado, as quais foram corrigidas segundo critério da paridade do poder de compra da moeda, que levou em conta as inflações doméstica e internacional. A taxa de câmbio real é assim obtida: 


$$
E=e \frac{\mathrm{Y}^{*}}{\mathrm{Y}}
$$

Em que $E$ é taxa real de câmbio no Brasil (R\$/ US\$); $e$, taxa nominal de câmbio no Brasil (R\$/US\$); $Y^{*}$, índice de preços internacionais (IPA dos Estados Unidos); e $Y$, índice de preços domésticos no atacado (IPA-DI). Vasconcelos (2015).

De acordo com essa metodologia, o preço em moeda nacional (preço doméstico) de um bem comercializado no mercado internacional pode ser obtido mediante o produto do preço em moeda estrangeira pela taxa de câmbio:

$$
\mathrm{P}_{\mathrm{RS}}=\mathrm{P}_{\text {uss }} * \mathrm{E}
$$

Em que $P_{R S}$ preço real em reais (R\$); $P_{U S S}$, preço nominal em dólar americano (US\$); e $E$, taxa real de câmbio (R\$/US\$).

Para obter a decomposição dos efeitos preço em dólar e câmbio, Reis e Campos (1998) fizeram uma adaptação da metodologia adotada por Yokoyama et al. (1989) e Silva e Carvalho (1995). Reis e Campos (1998) consideraram que o preço em reais é resultante do produto do preço em dólares pela taxa de câmbio brasileira.

A partir da expressão (2), obtém-se a expressão (3), que representa o preço do cacau em amêndoas em reais $(\mathrm{R} \$)$, em dado ano $t$ :

$$
\mathrm{PR}_{\mathrm{t}}=\mathrm{PD}_{\mathrm{t}} * \mathrm{E}_{\mathrm{t}}
$$

em que $\mathrm{PR}_{t}$ é preço real do cacau em amêndoas em reais $(\mathrm{R} \$) ; \mathrm{PD}_{\mathrm{t}}$, preço do cacau em amêndoas em dólares (US\$); e $E_{t}$, taxa de câmbio real do Brasil (R \$ US\$).

Os anos inicial e final são indicados pelos índices 0 e $t$, respectivamente. De forma idêntica à expressão (3), a expressão (4) mostra o preço real em reais ( $R$ \$), no período inicial 0 :

$$
\mathrm{PR}_{0}=\mathrm{PD}_{0} * \mathrm{E}_{0} \text {, }
$$

A expressão (5) mostra a variação no preço real em reais $(\mathrm{R} \$)$, quando ocorre somente variação no preço em dólares (US\$):

$$
\mathrm{PR}_{\mathrm{t}}^{\mathrm{PD}}=\mathrm{PD}_{\mathrm{t}}^{*} \mathrm{E}_{0},
$$

em que $\mathrm{PR}_{t}^{\mathrm{PD}}$ é o preço real do cacau em amêndoas no ano $t$, quando ocorre variação no preço em dólares (US\$) $\left(\mathrm{PD}_{\mathrm{t}}\right)$ e $\mathrm{E}$ se mantém constante $\left(\mathrm{E}_{\mathrm{o}}\right)$.

A expressão (6) mostra a variação no preço real em reais $(\mathrm{R} \$)$, quando ocorre somente variação na taxa de câmbio:

$$
\mathrm{PR}_{\mathrm{t}}^{\mathrm{E}}=\mathrm{PD}_{0} * \mathrm{E}_{\mathrm{t}}
$$

em que $\mathrm{PR}_{\mathrm{t}}^{\mathrm{E}}$ é o preço real do cacau em amêndoas no ano $t$, quando ocorre variação na taxa de câmbio e $P D$ se mantém fixo $\left(P D_{0}\right)$.

A mudança no preço em reais $(\mathrm{R} \$)$, entre o ano 0 e o período $t$, é assim expressa:

$$
\mathrm{PR}_{\mathrm{t}}-\mathrm{PR}_{0}=\left(\mathrm{PR}_{\mathrm{t}}^{\mathrm{PD}}-\mathrm{PR}_{0}\right)+\left(\mathrm{PR}_{\mathrm{t}}-\mathrm{PR}_{\mathrm{t}}^{\mathrm{PD}}\right)
$$

em que $P R_{t}-P R_{o}$ é a variação total nos preços reais do cacau em amêndoas em reais $(R \$) ; \mathrm{PR}_{\mathrm{t}}^{\mathrm{PD}}$ $\mathrm{PR}_{0}$, efeito preço internacional; e $\mathrm{PR}_{t}-\mathrm{PR}_{\mathrm{t}}^{\mathrm{PD}}$, efeito câmbio, pois, quando se retira do preço em reais ( $\mathrm{R} \$)$ no ano $t$ a variação do preço internacional em dólares (US\$), tem-se o efeito câmbio.

Os efeitos podem ser apresentados individualmente na forma de taxa de crescimento, os quais, somados, resultarão na taxa média anual de crescimento (Yokoyama et al., 1989).

Quando se multiplica ambos os lados da expressão (7) por $1 /\left(\mathrm{PR}_{\mathrm{t}}-\mathrm{PR}_{0}\right)$, obtém-se

$$
1=\left[\left(\mathrm{PR}_{\mathrm{t}}^{\mathrm{PD}}-\mathrm{PR}_{\mathrm{o}}\right) /\left(\mathrm{PR}_{\mathrm{t}}-\mathrm{PR}_{0}\right)\right]+\left[\left(\mathrm{PR}_{\mathrm{t}}-\mathrm{PR}_{\mathrm{t}}^{\mathrm{PD}}\right) /\left(\mathrm{PR}_{\mathrm{t}}-\mathrm{PR}_{0}\right)\right]
$$

A seguir, a multiplicação de ambos os lados da identidade (8) por $r$, que é taxa percentual anual total acumulada de variação no preço em reais (R\$) (efeito total), dada pela expressão ${ }^{4} r=\left[\left(P R_{t} / P R_{0}\right)^{1 / t}-1\right] \times 100$, leva a

$$
\mathrm{r}=\left[\left(\mathrm{PR}_{\mathrm{t}}^{\mathrm{PD}}-\mathrm{PRo}\right) /\left(\mathrm{PR}_{\mathrm{t}}-\mathrm{PR}_{0}\right)\right] * \mathrm{r}+\left[\left(\mathrm{PRt}^{-} \mathrm{PR}_{\mathrm{t}}^{\mathrm{PD}}\right) /\left(\mathrm{PR}_{\mathrm{t}}-\mathrm{PR}_{0}\right)\right] * \mathrm{r},
$$

em que $\left.\left[\left(\mathrm{PR}_{\mathrm{t}}^{\mathrm{PD}}-\mathrm{PR}_{0}\right) / \mathrm{PR}_{\mathrm{t}}-\mathrm{PR}_{0}\right)\right] \mathrm{x} r$ é o efeito preço internacional em dólares (US\$) acumulado, expresso em porcentagem-ano (efeito dólar); e [ $\left(P R_{t}-\right.$ $\left.\left.\left.P R_{t}^{P D}\right) / P R_{t}-P R o\right)\right] \mathrm{xr}$ é o efeito câmbio acumulado, expresso em porcentagem-ano (efeito câmbio). 
Adicionalmente, calculou-se o coeficiente de variação $(\mathrm{CV})$ da taxa de câmbio e do preço internacional do cacau em amêndoas. Essa medida de dispersão serviu para comparar o grau de homogeneidade das variáveis analisadas neste estudo. $\mathrm{O} C \mathrm{~V}$ é o desvio padrão expresso em porcentagem da média e é dado pela expressão

$$
\mathrm{CV}=\frac{\mathrm{S}}{\mathrm{X}} * 100
$$

em que $S$ é o desvio padrão amostral e $X$, a média.

${ }^{4} \mathrm{Na}$ análise acumulada anual, $\mathrm{t}$ varia de 0 a $\mathrm{n}$ anos, resultando numa taxa acumulada anual de variação. No viés ano a ano, t sempre será 1 .

Ao estudar os CV de diversos ensaios agrícolas, Pimentel-Gomes (1985) propôs uma classificação para o CV da seguinte forma: baixo, quando inferior a $10 \%$; médio, entre 10 e $20 \%$; alto, quando entre 20 e $30 \%$; e muito alto, quando são superiores a $30 \%$. A classificação do $\mathrm{CV}$ é inversamente proporcional à classificação da precisão do experimento, ou seja, quanto maior o CV menor a precisão experimental. Deste modo, CV baixo representa alta precisão, $\mathrm{CV}$ médio, média precisão, $\mathrm{CV}$ alto, baixa precisão e $\mathrm{CV}$ muito alto, muito baixa precisão.

Porém, neste trabalho propôs-se que a classificação do CV seja diretamente proporcional a classificação da instabilidade de preços, ou seja, quando maior o $\mathrm{CV}$ maior a instabilidade de preços. Deste modo, CV baixo representa baixa instabilidade, coeficiente médio, média instabilidade, $\mathrm{CV}$ alto, alta instabilidade e CV muito alto, muita instabilidade de preços.

\section{Resultados e Discussões}

\section{Resultados com os preços nominais}

Iniciaremos os resultados utilizando os preços internos nominais, ou seja, na formação de preços calculou-se os preços internos multiplicando os preços anuais cotados na bolsa de Nova York pelos câmbios nominais. Essa análise vai permitir comparar os ganhos dos produtores quando utilizam preços internos nominais e reais.

A Tabela 1 permite verificar que no ano de 1999 em relação a 1998 houve uma queda nos preços externos saindo de US\$1.601,63/t para US\$ 1.072,97/ t mas, devido a contribuição da desvalorização cambial quando esta saiu de R\$1,17/US\$ para R \$ 1,84/US\$, os preços internos nominais aumentaram passaram de $\mathrm{R} \$ 1.866,06$ para $\mathrm{R} \$ 1.976,69 / \mathrm{t}$. Se deixássemos variar só o câmbio o preço poderia atingir $\mathrm{R} \$ 2.950,62 / \mathrm{t}$. Tabela 1. Gráfico 2.

Analisando o ano de 2002 em relação a 2001 houve um aumento nos preços externos saindo de US\$ $1.034,32 / \mathrm{t}$ para US\$ $1.697,40 / \mathrm{t}$ mas, devido a contribuição da desvalorização cambial quando a taxa saiu de R\$2,35/US\$ para R \$ 2,93 /US\$, os preços internos nominais aumentaram, passando de $\mathrm{R} \$$ $2.432,12 / \mathrm{t}$ para $\mathrm{R} \$ 4.973,61 / \mathrm{t}$. Se deixássemos variar só o preço e fixássemos o câmbio este poderia atingir $\mathrm{R} \$ 3.991,29 / \mathrm{t}$. E se deixássemos o preço fixo e variássemos o câmbio o preço poderia ter chegado a $\mathrm{R} \$ 3.030,70 / \mathrm{t}$.

Já analisando o ano de 2020 em relação a 2019 podemos verificar que houve um pequeno aumento nos preços nominais externos saindo de US\$ $2.397,44 /$ t para US\$2.466,16/t mas, devido a uma boa contribuição da desvalorização cambial quando saiu de R $\$ 3,95 / \mathrm{US} \$$ para R \$ 5,16/US\$ em termos nominais, os preços internos nominais aumentaram consideravelmente, passando de $\mathrm{R} \$ 9.459,11 / \mathrm{t}$ para $\mathrm{R} \$$ $12.718,39 /$ t. Se deixássemos variar só o preço e fixássemos o câmbio este poderia atingir $\mathrm{R} \$ 9.730,24 /$ t. E se deixássemos o preço fixo e variássemos o câmbio o preço atingiria $\mathrm{R} \$ 12.363,99 /$ t. Como a variação da desvalorização cambial nominal $\mathrm{R} \$ 3,95 /$ $\mathrm{US} \$=>\mathrm{R} \$ 5,16 / \mathrm{US} \$=30,63 \%$ superou a taxa de inflação brasileira em 2020, que foi 4,52\%, significa que a competitividade do cacau em amêndoas aumentou em termos nominais.

Esse mesmo exercício com os preços nominais fazendo a decomposição de preços podemos verificar que os anos em que tiveram altas taxas de crescimento positivas foram: 2001 (56,3\% a.a.) 2002 (104,5\% a.a.), 2008 (26,5\% a.a., 2014 (35,6\% a.a.), 2015 (45,7\% a.a.), 2018 (32,4\% a.a.) e 2020 (34,5\% a.a.). Enquanto que nos anos em que houveram altas taxas de crescimento negativas foram 2000 (-21,3\% a.a.), 2004 (-15,6\% a.a.), 2005 (-17,3 \% a.a.), e 2017 (-35\% a.a.). Tabela 2.

No ano de 2002 verificou-se a mais alta taxa de crescimento positiva $104,15 \%$ a.a. O efeito preço teve uma maior participação com $64,1 \%$ e o efeito câmbio 
Tabela 1 - Efeitos preço e efeitos câmbios quando se utilizam preços internos nominais

\begin{tabular}{l|c|c|c|c|c}
\hline Ano & $\begin{array}{c}\text { Preços internos } \\
\text { Nominais } \\
\text { em R\$ }\end{array}$ & $\begin{array}{c}\text { Preços } \\
\text { Externos } \\
\text { em US\$ }\end{array}$ & $\begin{array}{c}\text { Taxa } \\
\text { nominal } \\
\text { de câmbio }\end{array}$ & $\begin{array}{c}\text { Efeito } \\
\text { Preço }\end{array}$ & $\begin{array}{c}\text { Efeito } \\
\text { Câmbio }\end{array}$ \\
\hline 1994 & $1.160,84$ & $1.324,02$ & 0,88 & & \\
1995 & $1.235,90$ & $1.350,05$ & 0,92 & $1.183,66$ & $1.212,07$ \\
1996 & $1.381,86$ & $1.370,41$ & 1,01 & $1.254,54$ & $1.361,32$ \\
1997 & $1.671,64$ & $1.544,44$ & 1,08 & $1.557,34$ & $1.483,28$ \\
1998 & $1.866,06$ & $1.601,63$ & 1,17 & $1.733,54$ & $1.799,43$ \\
1999 & $1.976,69$ & $1.072,97$ & 1,84 & $1.250,12$ & $2.950,62$ \\
2000 & $1.555,94$ & 850,84 & 1,83 & $1.567,48$ & $1.962,14$ \\
2001 & $2.432,12$ & $1.034,32$ & 2,35 & $1.891,46$ & $2.000,69$ \\
2002 & $4.973,61$ & $1.697,40$ & 2,93 & $3.991,29$ & $3.030,70$ \\
2003 & $5.254,15$ & $1.711,05$ & 3,07 & $5.013,59$ & $5.212,25$ \\
2004 & $4.432,07$ & $1.515,28$ & 2,92 & $4.653,00$ & $5.004,68$ \\
2005 & $3.664,23$ & $1.505,88$ & 2,43 & $4.404,58$ & $3.687,10$ \\
2006 & $3.356,96$ & $1.542,51$ & 2,18 & $3.753,36$ & $3.277,25$ \\
2007 & $3.693,41$ & $1.896,48$ & 1,95 & $4.127,33$ & $3.004,04$ \\
2008 & $4.672,40$ & $2.543,95$ & 1,84 & $4.954,37$ & $3.483,21$ \\
2009 & $5.611,59$ & $2.816,00$ & 1,99 & $5.172,06$ & $5.069,46$ \\
2010 & $5.237,45$ & $2.978,35$ & 1,76 & $5.935,10$ & $4.951,96$ \\
2011 & $4.930,50$ & $2.945,59$ & 1,67 & $5.179,84$ & $4.985,33$ \\
2012 & $4.586,88$ & $2.346,96$ & 1,95 & $3.928,48$ & $5.756,84$ \\
2013 & $5.209,27$ & $2.411,80$ & 2,16 & $4.713,60$ & $5.069,23$ \\
2014 & $7.063,34$ & $3.000,44$ & 2,35 & $6.480,67$ & $5.677,63$ \\
2015 & $10.289,67$ & $3.082,52$ & 3,34 & $7.256,59$ & $10.015,66$ \\
2016 & $9.883,26$ & $3.837,80$ & 3,48 & $9.472,77$ & $10.735,57$ \\
2017 & $6.427,19$ & $2.013,58$ & 3,19 & $7.012,74$ & $9.058,03$ \\
2018 & $8.511,95$ & $2.328,74$ & 3,66 & $7.433,16$ & $7.359,99$ \\
2019 & $9.459,11$ & $2.397,44$ & 3,95 & $8.763,05$ & $9.188,06$ \\
2020 & $12.718,39$ & $2.466,16$ & 5,16 & $9.730,24$ & $12.363,99$ \\
\hline & & & & & \\
\hline
\end{tabular}

Fonte: Dados da pesquisa

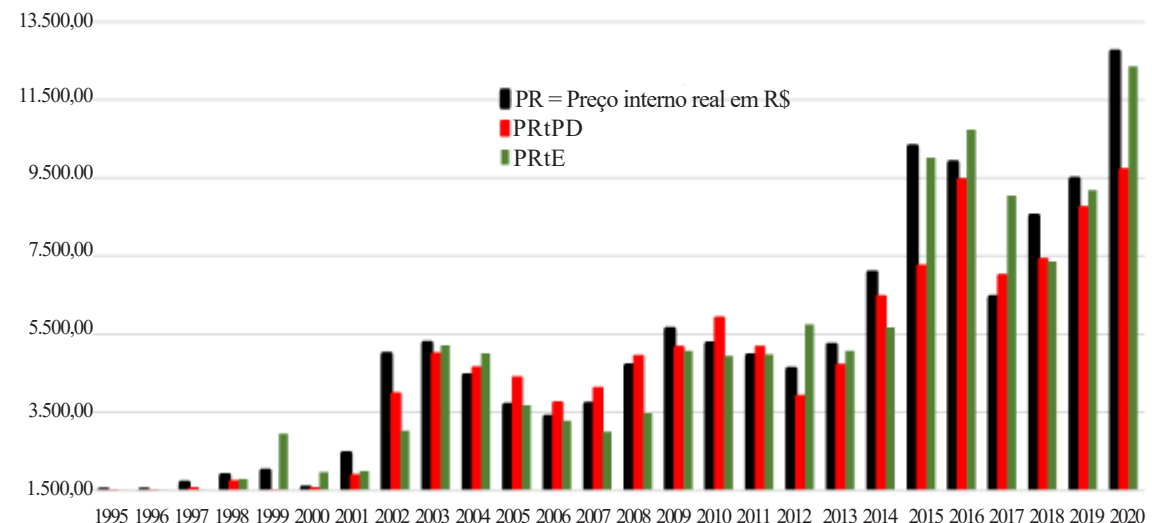

Fonte: Dados da pesquisa.

Gráfico 2 - Efeitos preços e efeitos câmbios quando se utilizam preços internos nominais variando preço e fixando câmbio e vice-versa. teve uma participação menor, porém positiva também de $40,4 \%$ a.a. Significando que ambos, tanto o efeito preço quanto o efeito câmbio contribuíram para o aumento da taxa de crescimento positiva. Porém, no ano de 2008 a taxa de crescimento positiva foi $26,5 \%$ a.a. mas, o efeito preço contribuiu sozinho para o aumento da taxa de crescimento com $34,1 \%$ enquanto que o efeito câmbio puxou os preços para baixo com uma participação negativa de $-7,6 \%$ a.a.

No ano de 2020 foi a vez do efeito câmbio contribuir consideravelmente na taxa de crescimento positiva de $34,5 \%$ a.a., com uma participação expressiva de $31,6 \%$ enquanto que o efeito preço só contribuiu com $2,9 \%$. Isto explica a alta desvalorização cambial de $\mathrm{R} \$$ 5,16 /US\$ elevando os preços internamente para $R \$ 12.363,99 / \mathrm{t}$ em termos nominais.

A mais baixa taxa de crescimento verificou-se em 2017 com $-35 \%$ a.a. quando o efeito preço teve uma maior participação de $-29 \%$ a.a. e o câmbio participação menor com $-5,9 \%$ a.a. mas, ambos contribuindo para uma redução de preços internos para os produtores de cacau. Tabela 2 e Gráfico 3.

\section{Resultados com os preços reais}

Analisou-se posteriormente os resultados utilizando os preços internos reais, ou seja, na formação de preços calculou-se os preços internos multiplicando os preços anuais cotados na bolsa de Nova York pelos câmbios reais, 
Tabela 2 - Decomposição da taxa anual de crescimento do preço do cacau em moeda nacional, 1994 a 2020

\begin{tabular}{|c|c|c|c|}
\hline Ano & $\begin{array}{l}\text { Efeito Total } \\
\qquad(\%)\end{array}$ & $\begin{array}{c}\text { Efeito Preço } \\
(\%)\end{array}$ & $\begin{array}{c}\text { Efeito Câmbio } \\
(\%)\end{array}$ \\
\hline \multicolumn{4}{|l|}{1994} \\
\hline 1995 & 6,5 & 2,0 & 4,5 \\
\hline 1996 & 11,8 & 1,5 & 10,3 \\
\hline 1997 & 21,0 & 12,7 & 8,3 \\
\hline 1998 & 11,6 & 3,7 & 7,9 \\
\hline 1999 & 5,9 & $-33,0$ & 38,9 \\
\hline 2000 & $-21,3$ & $-20,7$ & $-0,6$ \\
\hline 2001 & 56,3 & 21,6 & 34,7 \\
\hline 2002 & 104,5 & 64,1 & 40,4 \\
\hline 2003 & 5,6 & 0,8 & 4,8 \\
\hline 2004 & $-15,6$ & $-11,4$ & $-4,2$ \\
\hline 2005 & $-17,3$ & $-0,6$ & $-16,7$ \\
\hline 2006 & $-8,4$ & 2,4 & $-10,8$ \\
\hline 2007 & 10,0 & 22,9 & $-12,9$ \\
\hline 2008 & 26,5 & 34,1 & $-7,6$ \\
\hline 2009 & 20,1 & 10,7 & 9,4 \\
\hline 2010 & $-6,7$ & 5,8 & $-12,4$ \\
\hline 2011 & $-5,9$ & $-1,1$ & $-4,8$ \\
\hline 2012 & $-7,0$ & $-20,3$ & 13,4 \\
\hline 2013 & 13,6 & 2,8 & 10,8 \\
\hline 2014 & 35,6 & 24,4 & 11,2 \\
\hline 2015 & 45,7 & 2,7 & 42,9 \\
\hline 2016 & $-3,9$ & $-7,9$ & 4,0 \\
\hline 2017 & $-35,0$ & $-29,0$ & $-5,9$ \\
\hline 2018 & 32,4 & 15,7 & 16,8 \\
\hline 2019 & 11,1 & 2,9 & 8,2 \\
\hline 2020 & 34,5 & 2,9 & 31,6 \\
\hline
\end{tabular}

Fonte: Dados da pesquisa onde qualquer variação isolada ou em conjunto nesses fatores pode afetar os preços domésticos. Essa análise permitiu verificar os pseudos ganhos do mercado interno quando utilizaram preços da tonelada de cacau sem a devida correção. Ou seja, por exemplo, se a desvalorização cambial utilizada na formação dos preços internos for na mesma proporção da inflação brasileira, na realidade, não houve uma desvalorização em termos reais. A desvalorização nominal será na proporção devida, mas, a real é nula. Consequentemente não haverá aumento de competitividade do produto em questão.

O Gráfico 4 mostra que durante a implantação do plano real até hoje, tanto os preços internacionais do cacau em amêndoas como a taxa de câmbio apresentaram-se oscilações. O mesmo acontece com os preços em moeda nacional (em reais), que sofreram grande influência dessas variações.

Conforme a Tabela 3 no período entre 1994 e 2020 podemos verificar que nos anos de 2002 e 2003 e entre 2014 a 2020, com exceção de 2017, o preço médio anual real do cacau em moeda nacional foi superior à média do período que foi de R $\$ 2.865 /$ t. Esse preço chegou a seu valor máximo em 2015, quando atingiu $\mathrm{R} \$ 4.597 / \mathrm{t}$ e o seu valor mínimo no ano de 2000 quando atingiu $\mathrm{R} \$ 1.692 / \mathrm{t}$.

Já a taxa de câmbio real teve seu ápice em 2002 coincidindo com a alta dos preços reais, R \$2,42/US\$,

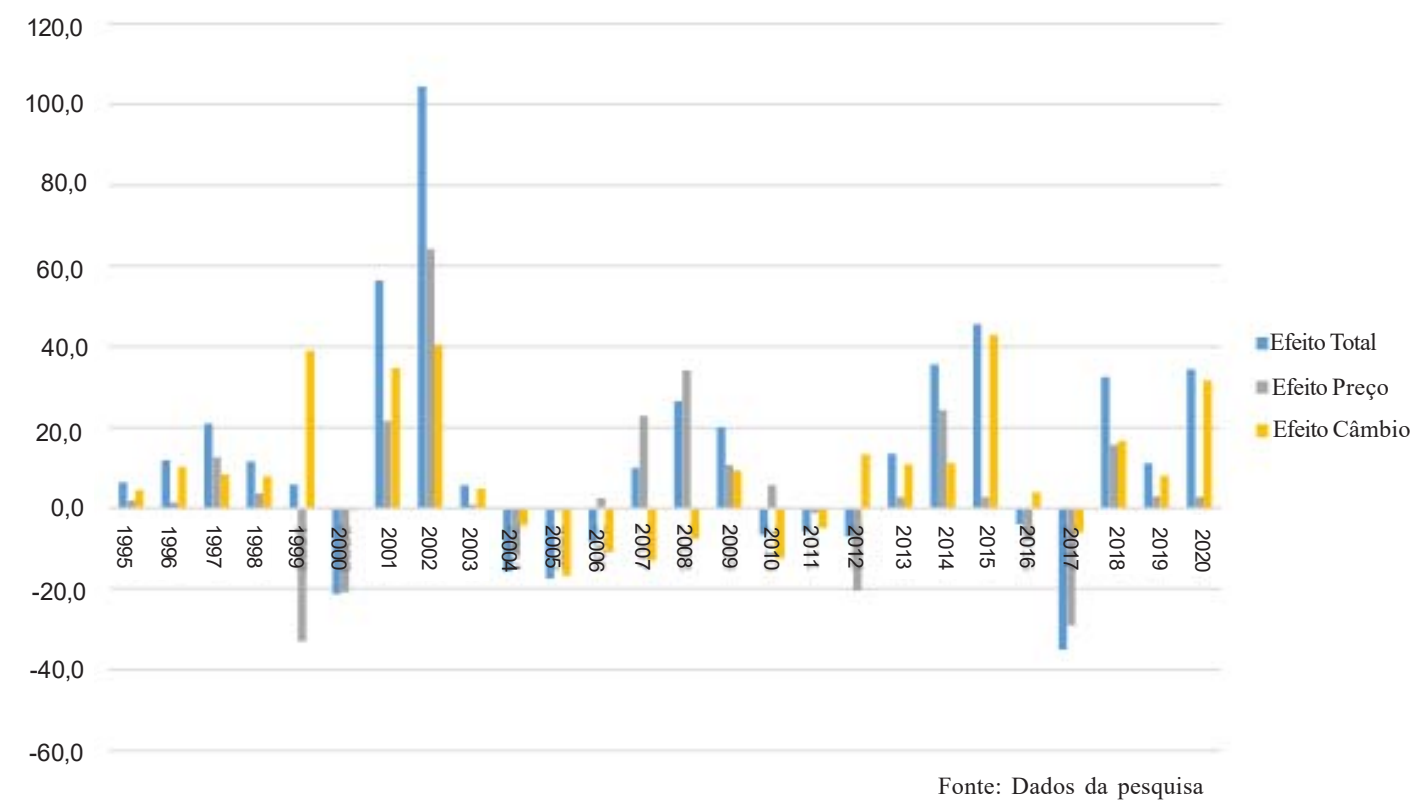

Gráfico 3 - Efeitos preço, efeito câmbio e efeito total nominais entre 1995 e 2020. 
Tabela 3 - Valores dos preços reais $(\mathrm{R} \$ / \mathrm{t})$ e dos preços nominais de cacau em amêndoas (US\$/t) e da taxa real de câmbio bilateral (US\$/R\$) - Período 1994-2020

\begin{tabular}{|c|c|c|c|}
\hline $\begin{array}{l}\text { Preçc } \\
\text { cacal }\end{array}$ & $\begin{array}{l}\text { eços reais do } \\
\text { acau em } \mathrm{R} \$ / \mathrm{t}\end{array}$ & $\begin{array}{c}\text { Preços nominais } \\
\text { do cacau em US\$/t }\end{array}$ & $\begin{array}{c}\text { Taxa de câmbio real } \\
\text { bilateral US\$/R\$ }\end{array}$ \\
\hline 1994 & 2.134 & 1.324 & 1,61 \\
\hline 1995 & 1.940 & 1.350 & 1,44 \\
\hline 1996 & 2.077 & 1.370 & 1,52 \\
\hline 1997 & 2.462 & 1.544 & 1,59 \\
\hline 1998 & 2.633 & 1.602 & 1,64 \\
\hline 1999 & 2.409 & 1.073 & 2,25 \\
\hline 2000 & 1.692 & 851 & 1,99 \\
\hline 2001 & 2.385 & 1.034 & 2,31 \\
\hline 2002 & 4.100 & 1.697 & 2,42 \\
\hline 2003 & 3.544 & 1.711 & 2,07 \\
\hline 2004 & 2.804 & 1.515 & 1,85 \\
\hline 2005 & 2.297 & 1.506 & 1,53 \\
\hline 2006 & 2.151 & 1.543 & 1,39 \\
\hline 2007 & 2.330 & 1.896 & 1,23 \\
\hline 2008 & 2.743 & 2.544 & 1,08 \\
\hline 2009 & 3.229 & 2.816 & 1,15 \\
\hline 2010 & 2.978 & 2.978 & 1,00 \\
\hline 2011 & 2.710 & 2.946 & 0,92 \\
\hline 2012 & 2.424 & 2.347 & 1,03 \\
\hline 2013 & 2.628 & 2.412 & 1,09 \\
\hline 2014 & 3.476 & 3.000 & 1,16 \\
\hline 2015 & 4.597 & 3.083 & 1,49 \\
\hline 2016 & 3.956 & 2.838 & 1,39 \\
\hline 2017 & 2.668 & 2.014 & 1,32 \\
\hline 2018 & 3.398 & 2.329 & 1,46 \\
\hline 2019 & 3.558 & 2.397 & 1,48 \\
\hline 2020 & 4.029 & 2.466 & 1,63 \\
\hline Média & 2.865 & 2.007 & 1,52 \\
\hline Desvio Padrão & o 750,78 & 665,42 & 0,43 \\
\hline C.V. & 24,8 & 30,4 & 29,2 \\
\hline
\end{tabular}

Fonte: ICCO; BCB e Instituto de Pesquisas Aplicadas - IPEA

a partir daí teve uma queda considerável chegando ao fundo do poço em 2011, chegando a R \$ 0,92/US\$, situando-se abaixo da média que foi de R \$1,52/US\$, quando começou uma reação chegando em 2020 (R\$ 1,63/US\$) chegando praticamente aos mesmos níveis de 1998 (R\$ 1,64/US\$). Tabela 3 e Gráfico 4.

Considerando-se a política cambial adotada no plano real, até 1998 o câmbio não variou muito devido a estabilidade do referido plano e do regime de bandas cambiais apresentando baixa sua amplitude, porém a partir de 1999 com o câmbio flutuante, as variações na taxa de câmbio contribuíram de certa importância para a variabilidade dos preços do cacau em moeda nacional.
Para Silva e Carvalho (1995), a variação real do câmbio tanto pode elevar como reduzir a variabilidade dos preços em moeda nacional. Aumentará a variabilidade se, predominantemente, nos períodos em que a moeda estiver valorizada, os preços em dólares estiverem em queda e vice-versa. Se acontecer o inverso, a instabilidade será menor quando calculada sobre os preços em moeda nacional.

Analisando o coeficiente de variação (C.V.) podese observar que os preços reais em moeda nacional tiveram alta instabilidade (C.V. $=24,8 \%)$. Essa variação decorreu em maior proporção, pois os coeficientes de variação do efeito preço apresentou instabilidade muito alta (C.V. $=30,4 \%)$ e do efeito câmbio que apresentou alta instabilidade (C.V. $=29,2 \%$ ), isto sem contar com a inflação do período do real que foi relativamente baixa.

A Tabela 4 permite verificar que no ano de 1998 em relação a 1997 houve um aumento nos preços externos saindo de US\$ $1.544,44 / \mathrm{t}$ para US\$ $1.601,63 / \mathrm{t}$ mas, devido à contribuição da desvalorização cambial quando esta saiu de $\mathrm{R} \$ 1,59$ / US\$ para R\$ 1,64/US\$, os preços internos reais aumentaram passando de $\mathrm{R} \$ 2.462,04$ para $\mathrm{R} \$$ $2.633,04 /$ t. Se fixássemos o preço e deixássemos variar só o câmbio o preço poderia atingir R\$ 2.539,02. Tabela 4. Gráfico 5.

Analisando o ano de 2002 em relação a 2001 houve um aumento nos preços externos saindo de US\$ $1.034,32 / \mathrm{t}$ para US\$1.697,40/t mas, devido à contribuição da desvalorização cambial quando saiu de $\mathrm{R} \$ 2,31 / \mathrm{US} \$$ para R 2,42 /US\$, os preços internos nominais aumentaram, passaram de $\mathrm{R} \$ 2.385,35$ para $\mathrm{R} \$ 4.099,85 / \mathrm{t}$. Se deixássemos variar só o preço e fixássemos o câmbio este poderia atingir $\mathrm{R} \$ 3.914,54$. E se deixássemos o preço fixxo e variássemos o câmbio o preço poderia chegar a $\mathrm{R} \$ 2.498,27$.

Já analisando o ano de 2020 em relação a 2019 podemos verificar que houve um pequeno aumento nos preços externos saindo de US\$ $2.397,44 / t$ para US\$ 2.466,16/t mas, devido a contribuição da desvalorização do câmbio quando este saiu de R \$1,48/US\$ para R\$ $1,63 /$ US\$, os preços internos reais não aumentaram consideravelmente mais do que quando usados os câmbios nominais, passaram de $\mathrm{R} \$ 3.558,34$ para $\mathrm{R} \$$ $4.029,21 /$ t. Se deixássemos variar só o preço e fixássemos o câmbio este poderia atingir $\mathrm{R} \$ 3.660,34$. 


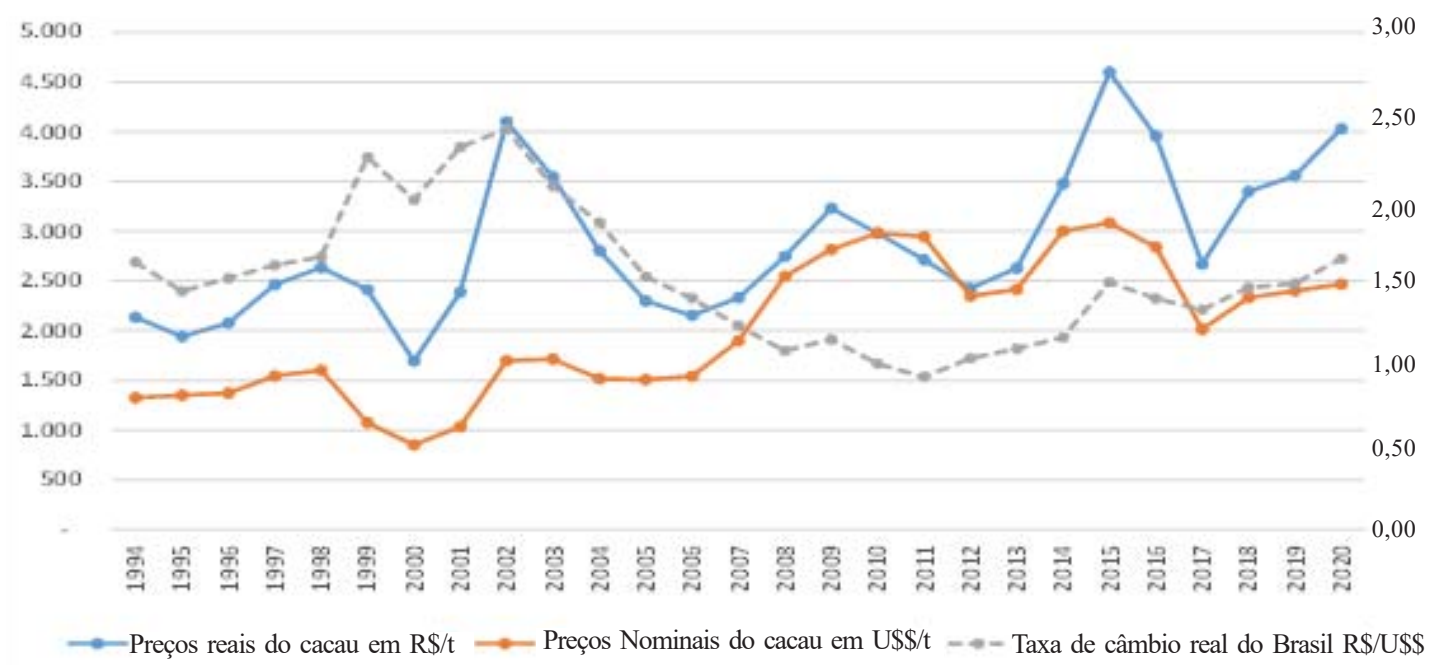

Fonte: Organização Internacional de Cacau e Café - ICCO e Banco Central do Brasil - BCB.

Gráfico 4 - Comportamento dos preços médios anuais do cacau em amêndoas em reais e em dólares e da taxa média anual de câmbio real do Brasil, 1975 a 2020.

Tabela 4 - Efeitos preço e efeitos câmbios quando se utilizam preços internos reais

\begin{tabular}{|c|c|c|c|c|c|}
\hline Ano & $\begin{array}{c}\text { Preços internos } \\
\text { Nominais } \\
\text { em R\$ }\end{array}$ & $\begin{array}{c}\text { Preços } \\
\text { Externos } \\
\text { em US\$ }\end{array}$ & $\begin{array}{c}\text { Taxa } \\
\text { nominal } \\
\text { de câmbio }\end{array}$ & $\begin{array}{l}\text { Efeito } \\
\text { Preço }\end{array}$ & $\begin{array}{c}\text { Efeito } \\
\text { Câmbio }\end{array}$ \\
\hline 1994 & $2.133,80$ & $1.324,02$ & 1,61 & & \\
\hline 1995 & $1.940,39$ & $1.350,05$ & 1,44 & $2.175,75$ & $1.902,98$ \\
\hline 1996 & $2.077,25$ & $1.370,41$ & 1,52 & $1.969,66$ & $2.046,39$ \\
\hline 1997 & $2.462,25$ & $1.544,44$ & 1,59 & $2.341,04$ & $2.184,80$ \\
\hline 1998 & $2.633,04$ & $1.601,63$ & 1,64 & $2.553,42$ & $2.539,02$ \\
\hline 1999 & $2.409,48$ & $1.072,97$ & 2,25 & $1.763,93$ & $3.596,65$ \\
\hline 2000 & $1.692,28$ & 850,84 & 1,99 & $1.910,68$ & $2.134,08$ \\
\hline 2001 & $2.385,35$ & $1.034,32$ & 2,31 & $2.057,21$ & $1.962,22$ \\
\hline 2002 & $4.099,85$ & $1.697,40$ & 2,42 & $3.914,54$ & $2.498,27$ \\
\hline 2003 & $3.544,42$ & $1.711,05$ & 2,07 & $4.132,81$ & $3.516,15$ \\
\hline 2004 & $2.803,90$ & 1515,28 & 1,85 & $3.138,88$ & $3.166,16$ \\
\hline 2005 & $2.297,47$ & $1.505,88$ & 1,53 & $2.786,51$ & $2.311,81$ \\
\hline 2006 & $2.151,09$ & $1.542,51$ & 1,39 & $2.353,35$ & $2.100,01$ \\
\hline 2007 & $2.330,23$ & $1.896,48$ & 1,23 & $2.644,73$ & $1.895,29$ \\
\hline 2008 & $2.743,20$ & $2.543,95$ & 1,08 & $3.125,78$ & $2.045,02$ \\
\hline 2009 & $3.229,39$ & $2.816,00$ & 1,15 & $3.036,56$ & $2.917,40$ \\
\hline 2010 & $2.978,35$ & $2.978,35$ & 1,00 & $3.415,57$ & $2.816,00$ \\
\hline 2011 & $2.710,22$ & $2.945,59$ & 0,92 & $2.945,59$ & $2.740,36$ \\
\hline 2012 & $2.423,93$ & $2.346,96$ & 1,03 & $2.159,43$ & $3.042,19$ \\
\hline 2013 & $2.628,35$ & $2.411,80$ & 1,09 & $2.490,89$ & $2.557,69$ \\
\hline 2014 & $3.475,51$ & $3.000,44$ & 1,16 & 3.269 .84 & $2.793,67$ \\
\hline 2015 & $4.596,67$ & $3.082,52$ & 1,49 & $3.570,60$ & $4.474,26$ \\
\hline 2016 & $3.955,65$ & $2.837,80$ & 1,39 & $4.231,73$ & $4.296,78$ \\
\hline 2017 & $2.667,65$ & $2.013,58$ & 1,32 & $2.806,76$ & $3.759,59$ \\
\hline 2018 & $3.397,79$ & $2.328,74$ & 1,46 & $3.085,18$ & $2.937,95$ \\
\hline 2019 & $3.558,34$ & $2.397,44$ & 1,48 & $3.498,03$ & $3.456,38$ \\
\hline 2020 & $4.029,21$ & $2.466,16$ & 1,63 & $3.660,34$ & $3.916,94$ \\
\hline
\end{tabular}

Fonte: Dados da pesquisa
E se deixássemos o preço fixo e variássemos o câmbio o preço atingiria $\mathrm{R} \$ 3.916,94$.

Como a variação da desvalorização cambial real $\mathrm{R} \$$ $1,48 / \mathrm{US} \$=>\mathrm{R} \$ 1,63 / \mathrm{US} \$=$ $10,14 \%$ superou menos a taxa de inflação brasileira $4,52 \%$, do que quando usamos a variação da desvalorização nominal (30,63\%), podemos dizer que a competitividade do cacau em amêndoas aumentou bem menos em termos reais.

Tomando o ano de 2020 como referência, essa pequena desvalorização cambial em termos reais ( $\mathrm{R} \$ 1,63 / \mathrm{US} \$$ ), quando comparada com a desvalorização nominal (US\$ 5,16/US\$), pode ser explicado porque a inflação no Brasil em 2020 foi de 4,52\% enquanto que a inflação nos Estados Unidos foi de $1,36 \%$, praticamente mantendo a mesma relação, já que o índice usado foi o bilateral entre Brasil e Estados Unidos fornecido pelo IPEA. Portanto, explica-se o preço interno nominal de $\mathrm{R} \$$ $12.718,39 / \mathrm{t}$ e o preço interno real 


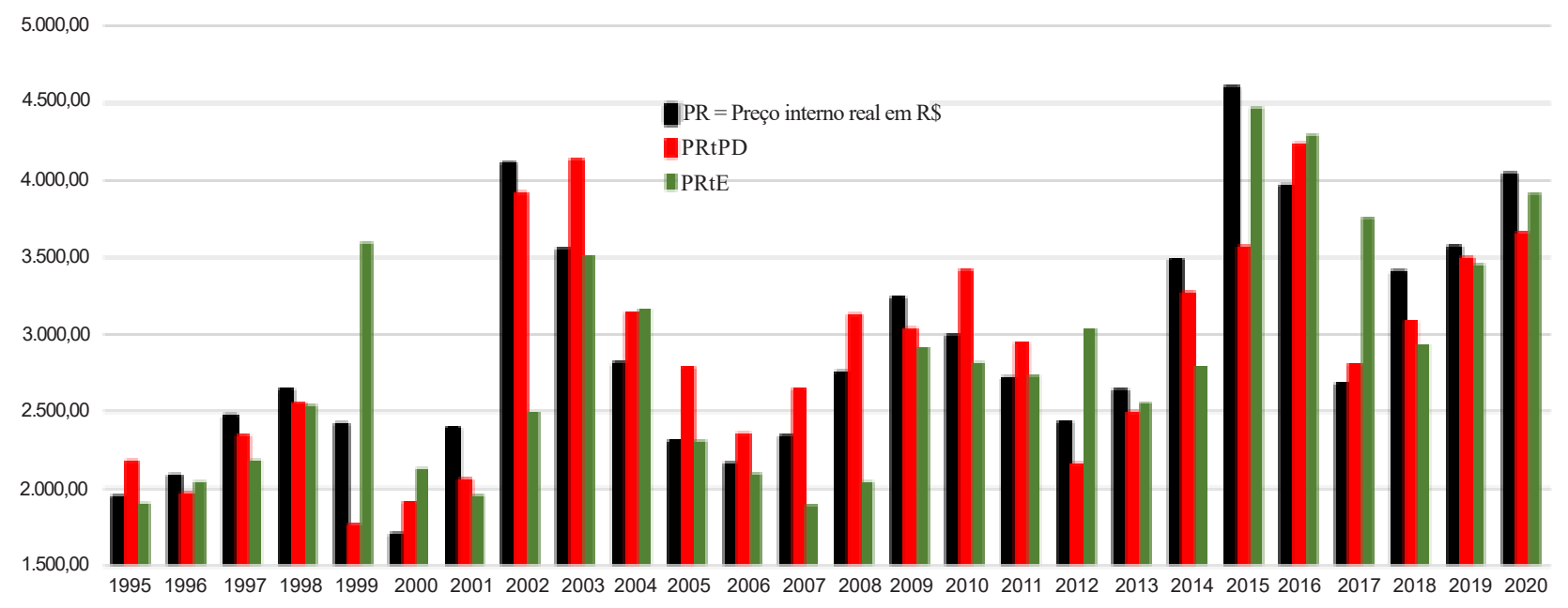

Fonte: Dados da pesquisa

Gráfico 5 - Efeitos preços e efeitos câmbios quando se utilizam preços internos reais variando preço e fixando câmbio e vice-versa.

$\mathrm{R} \$ 4.029,21 / \mathrm{t}$, anulando boa parte da desvalorização cambial. Tabela 4 e Gráfico 5.

Na Tabela 5, são apresentados os resultados da aplicação do modelo shift-share para análise dos efeitos do preço internacional e da taxa de câmbio sobre o preço doméstico do cacau em amêndoas. Mostram-se os resultados obtidos na decomposição dos preços internacionais do cacau em moeda nacional. Observou-se que ocorreram grandes variações dos preços internacionais do cacau em moeda nacional, quando se calculou as taxas anuais de crescimento (efeito total). Os preços reais do cacau apresentaram alta instabilidade, os preços nominais apresentaram muito alta instabilidade e o câmbio real apresentaram alta instabilidade.

A maior variação na taxa de crescimento dos preços do cacau ocorreu em 2002, chegando a 71,9\% a.a. (efeito total). Esse aumento no preço em moeda nacional teve como principal contribuição o aumento do preço em dólar (efeito preço), que variou cerca de $64,1 \%$ a.a., acompanhado de uma variação de 7,8\% a.a. na taxa de câmbio (efeito câmbio). Já a segunda maior variação na taxa de crescimento dos preços do cacau ocorreu em 2001, com $41 \%$ a.a., quando as contribuições dos efeitos preço e câmbio foram proporcionais, enquanto o efeito preço variou em $21,6 \%$ a.a. o efeito câmbio variou em $19,4 \%$ a.a. Tabela 5 .
Tabela 5 - Decomposição da taxa anual de crescimento do preço do cacau em moeda nacional, 1994 a 2020

\begin{tabular}{|c|c|c|c|}
\hline Ano & $\begin{array}{c}\text { Efeito Total } \\
(\%)\end{array}$ & $\begin{array}{c}\text { Efeito Preço } \\
(\%)\end{array}$ & $\begin{array}{c}\text { Efeito Câmbio } \\
(\%)\end{array}$ \\
\hline \multicolumn{4}{|l|}{1994} \\
\hline 1995 & $-9,1$ & 2,0 & $-11,0$ \\
\hline 1996 & 7,1 & 1,5 & 5,5 \\
\hline 1997 & 18,5 & 12,7 & 5,8 \\
\hline 1998 & 6,9 & 3,7 & 3,2 \\
\hline 1999 & $-8,5$ & $-33,0$ & 24,5 \\
\hline 2000 & $-29,8$ & $-20,7$ & $-9,1$ \\
\hline 2001 & 41,0 & 21,6 & 19,4 \\
\hline 2002 & 71,9 & 64,1 & 7,8 \\
\hline 2003 & $-13,5$ & 0,8 & $-14,4$ \\
\hline 2004 & $-20,9$ & $-11,4$ & $-9,5$ \\
\hline 2005 & $-18,1$ & $-0,6$ & $-17,4$ \\
\hline 2006 & $-6,4$ & 2,4 & $-8,8$ \\
\hline 2007 & 8,3 & 22,9 & $-14,6$ \\
\hline 2008 & 17,7 & 34,1 & $-16,4$ \\
\hline 2009 & 17,7 & 10,7 & 7,0 \\
\hline 2010 & $-7,8$ & 5,8 & $-13,5$ \\
\hline 2011 & $-9,0$ & $-1,1$ & $-7,9$ \\
\hline 2012 & $-10,6$ & $-20,3$ & 9,8 \\
\hline 2013 & 8,4 & 2,8 & 5,7 \\
\hline 2014 & 32,2 & 24,4 & 7,8 \\
\hline 2015 & 32,3 & 2,7 & 29,5 \\
\hline 2016 & $-13,9$ & $-7,9$ & $-6,0$ \\
\hline 2017 & $-32,6$ & $-29,0$ & $-3,5$ \\
\hline 2018 & 27,4 & 15,7 & 11,7 \\
\hline 2019 & 4,7 & 2,9 & 1,8 \\
\hline 2020 & 13,2 & 2,9 & 10,4 \\
\hline
\end{tabular}

Fonte: Dados da pesquisa 


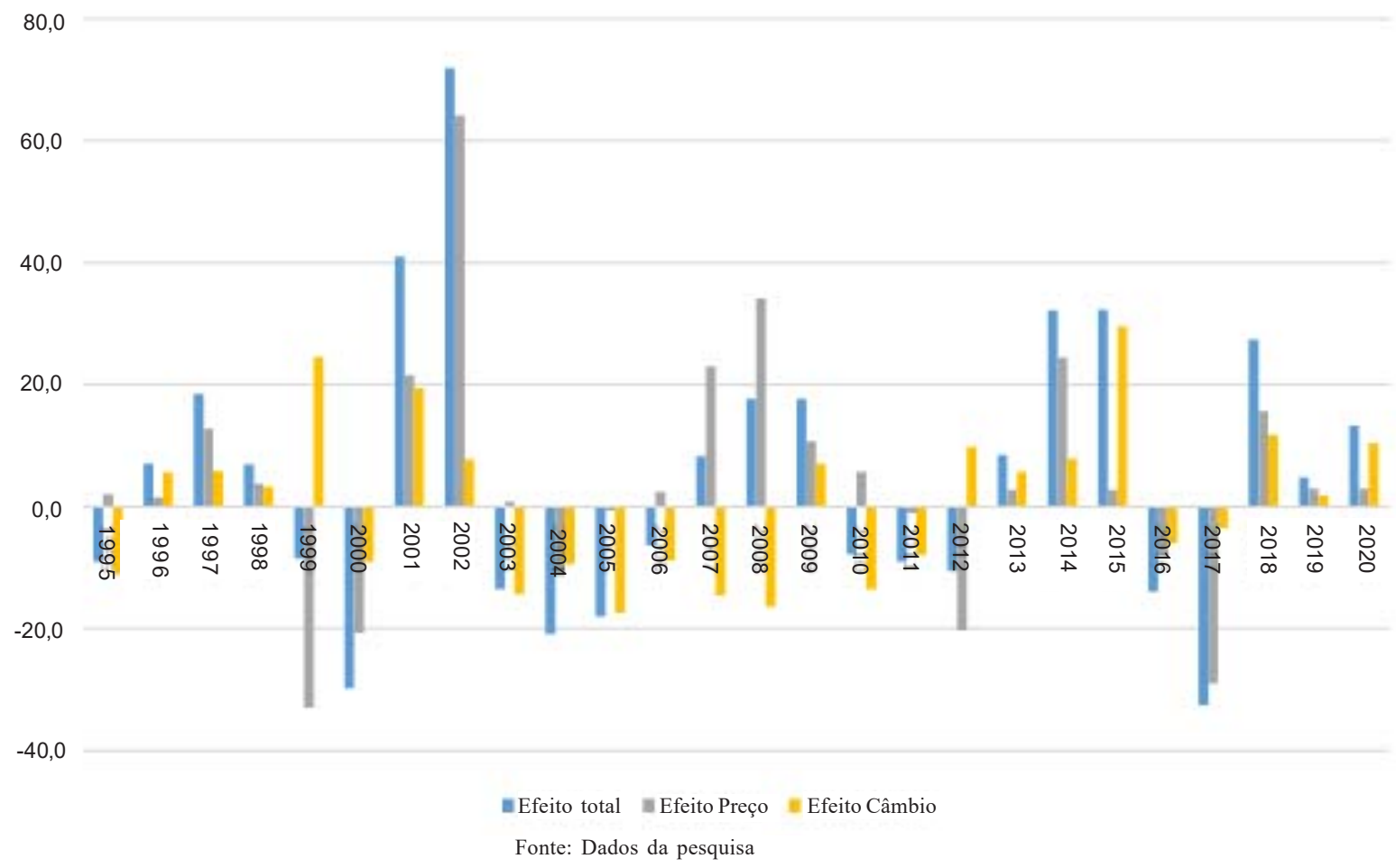

Gráfico 6 - Efeitos preço, efeito câmbio e efeito total reais entre 1995 e 2020.

Com relação ao preço internacional, o maior efeito positivo, foi observado no ano de $2002,64,1 \%$ a.a. (Tabela 5). A entrada num novo ciclo de alta, ocasionado pelo consumo mundial maior que a produção, determinou esse valor. $\mathrm{O}$ maior efeito negativo foi observado em 1999, $-33 \%$ a.a., consequência do aumento da oferta mundial proporcionada pelo crescimento da produção de cacau em amêndoas. Já com relação ao câmbio, o maior efeito positivo da taxa de câmbio ocorreu em 2002, (71,9\% a.a.), e o maior efeito negativo, em 2017 (-32,9\% a.a.), o que comprovou a influência da instabilidade econômica vigente no período analisado.

Só em 2014 e 2015 maiores variações positivas, ou alta, voltaram a ocorrer com os efeitos totais variando com 32,2\% a.a. e 32,3\% a.a., respectivamente. Sendo que em 2014 a variação no preço, ou efeito preço, prevaleceu com $24,4 \%$ a.a. e o efeito câmbio com $7,8 \%$ a.a. e em 2015 a variação no câmbio, ou efeito câmbio, prevaleceu com $29,5 \%$ a.a. e o efeito preço com $2,7 \%$ a.a.
Enquanto que as maiores variações ou oscilações negativas, ou quedas, ocorreram em 2000 e 2017 , quando a taxa de crescimento negativa foram $-32,6 \%$ e $-29,8 \%$, respectivamente. As variações tanto em 2000, assim como, em 2017, prevaleceram os efeitos preços com quedas de $-20,7 \%$ e $-29 \%$, respectivamente. Enquanto o efeito câmbio tiveram pequenas oscilações negativas $-9,1 \%$ e $-3,5 \%$, respectivamente.

Os anos em que o efeito preço tiveram predominância no efeito total foram 1997, 2000, 2002, 2008, 2012, 2014 e 2017. Enquanto que os anos em que o efeito câmbio prevaleceram no efeito total foram 1995, 2003, 2005, 2006, 2010 , 2011, 2015 e 2020. Nos anos não citados entre 1994 e 2020 os efeitos preço e os efeitos câmbio se equivaleram ou não variaram muito. Tabela 5 e Gráfico 6.

A menor variação na taxa de crescimento dos preços do cacau ocorreu em 2019, chegando a $4,7 \%$. Essa taxa é composta pela soma dos efeitos preço de $2,9 \%$ e efeito câmbio $1,8 \%$. 


\section{Conclusões}

Conclui-se que no período estudado de 1994 a 2020, referente ao plano real, verifica-se que a participação do efeito preço na formação do preço interno real foi mais contundente do que o efeito câmbio, confirmando os resultados obtidos por Reis e Campos (1998), no período entre 1975 a 1995 e também por Soares, Costa e Lemos (2016) no período entre 1990 a 2010.

$\mathrm{O}$ ano de 2002 teve a maior taxa de crescimento (efeito total) de $71 \%$ a.a. proporcionando participação positiva nos preços (efeito preços) de 64\% a.a. Assim como, o ano de 2017 teve a menor taxa de crescimento (efeito total) de $-32,6 \%$ a.a. proporcionado participação negativa no preço (efeito preço) com queda de -29\% a.a., como também, uma participação negativa no câmbio de $-3,5 \%$ a.a., ambos contribuindo para termos uma taxa de crescimento negativa. Entre 2003 e 2011 o fator câmbio teve uma influência negativa muito grande nas taxas de crescimento negativa, mesmo quando obteve-se efeitos totais positivos neste período, o efeito câmbio sempre se comportou com variações negativas, tendo menores participações na formação dos preços reais domésticos, destacando-se uma participação positiva somente nos anos 2015, 2016 e 2020. As diferenças de inflação entre Brasil e Estados Unidos contribuíram para reduzir o efeito da taxa de câmbio real no ano de 2020, praticamente anulando a desvalorização cambial. Porém, se não houvesse a desvalorização cambial adotada a perda de competitividade do cacau em amêndoas seria bem maior.

\section{Literatura Citada}

ARAÚJO, A. C.; MIDLEJ, R. R.; SILVA, L. M. R. 2004. Valor da produção de cacau e análise dos fatores responsáveis pela sua variação no estado da Bahia. CEPEC/SUBES/CEPLAC.

CURTIS, W. C. 1972. Shift-Share Analysis as a technique in rural development research. American Journal of Agricultural Economics 54(2):267-70.
PIRES, M. de M; GOMES, M. F. M.; ALVES, J. M. 2004. Fatores de crescimento das receitas de exportações brasileiras de café. In: Congresso Brasileiro de Economia e Sociologia Rural, 42. 2004, Cuiabá, MT. Anais... Cuiabá, MT, SOBER, 1. CD-ROM.

REIS, S. M. dos; CAMPOS, R. T. 1998. Efeitos da taxa de câmbio sobre os preços do cacau. In: Congresso Brasileiro de Economia e Sociologia Rural, 17. 1998. Poços de Caldas. Anais... Brasília, DF, SOBER, 2. pp.89-100.

SILVA, C. R. L.; CARVALHO, M. A. 1995. Taxa de câmbio e preços de commodities agrícolas. Informações Econômicas (Brasil) 25(5):23-35.

SOUSA, L. O. de; FERREIRA, M. P. F.; TEIXEIRA, E. C. 2007. Café solúvel Impacto dos preços e taxa de câmbio. Revista de Política Agrícola. MAPA. Ano XVI - No 3 - jul./ago./set. 2007.

SOARES, N. S.; SILVA, M. L. da; ROSSMANN, H. 2013. Influência da taxa de câmbio e do dólar sobre os preços da borracha natural brasileira. Revista Árvore (Brasil) 37(2):339-346.

SOARES, N. S.; COSTA, F. M.; LEMOS, R. M. 2016. Efeito da taxa de câmbio do Brasil e do dólar sobre os preços do cacau. In: Cacau Riqueza dos Pobres. Editus-Uesc (http://www.uesc.br/editora/ livrosdigitais2016/cacau_riqueza_pobres.pdf) pp.129-142.

VASCONCELOS, M. A. S. de. 2015. Economia Micro e Macro. $6^{\text {a }}$ edição. São Paulo, SP, Atlas.

YOKOYAMA, L. P.; IGREJA, A. C. M.; NEVES, E. M. 1989. Modelo shift-share: uma readaptação metodológica e uma aplicação para o Estado de Goiás. In: Congresso Brasileiro de Economia e Sociologia Rural, 27. 1989. Piracicaba, SP. Anais... Brasília, DF, SOBER, 1.pp.62-78.

ZUGAIB, A. C. C. 2008. Mudanças cambiais e o 
efeito dos fatores de crescimento ou declínio nas receitas de exportações brasileiras de cacau em amêndoas. Revista Bahia Agrícola (Brasil) 8(2):43-38.
ZUGAIB, A. C. C. 2021. O mercado nacional e internacional de cacau em amêndoas e derivados. Boletim Técnico 222. CEPEC/ SUBES/CEPLAC. 72p. 